\title{
Introduction to De Economist Special Issue "Retirement and Employment Opportunities for Older Workers"
}

\author{
Pierre Koning
}

Received: 10 July 2013 / Accepted: 11 July 2013 / Published online: 30 July 2013

(C) Springer Science+Business Media New York 2013

Since the seminal work of Gruber and Wise (1999), for many countries there is a continuing stream of papers that addresses the role of financial incentives in the retirement decision of workers. Generally, these papers show that workers do respond to incentives that encourage them to retire later, thus contributing to a sufficiently large workforce and adding to the sustainability of pension systems. At the same time, many Western European countries have gone through a process of pension system reforms, with benefit cuts, higher statutory pensioning ages and stricter eligibility constraints as most common policy measures. And while labor participation rates of older individuals have increased as a result of this, the new question has risen how the additional of older labor supply should be mobilized at best—-thus tackling the so called 'age-productivity-pay nexus'. ${ }^{1}$

While there is consensus on the impact of financial incentives on retirement behavior, the desirability of pension reforms is still highly disputed in most countries. In light of the current global economic crisis, this is not very surprising. With low or even negative economic growth, increasing retirement age seems less urgent, orfrom another perspective-can even be perceived as 'unfair' to younger workers who face a high risk of unemployment. At the same time, if older workers become unemployed, they typically have low return-to-work rates. Increasing statutory retirement ages may therefore lead to an increased use of other schemes, like Unemployment Insurance, Social Assistance or Disability Insurance. Understanding these mechanisms is important in assessing the overall desirability of pension reforms. Unfortunately, the evidence on these matters is still scarce, particularly on the income effects of reforms

\footnotetext{
1 See for more information on this topic, the Special Issue of De Economist on Ageing Workforces (Vandenberghe 2011).
}

P. Koning $(\bowtie)$

Department of Economics, VU University Amsterdam,

De Boelelaan 1105, P.O. Box 80510, 1081 HV Amsterdam, The Netherlands

e-mail: p.w.c.koning@vu.nl 
for (subgroups of) older workers. Without knowledge on the heterogeneity in reforms effects, for policymakers it is hard to assess the equity and efficiency trade-offs of their proposals.

The six papers in this special issue of De Economist intend to provide an integrative empirical analysis of the effects of pension and labor market reforms for older workers. They do not only consider the direct, behavioral effects of reforms, but also assess effects on income, work opportunities for older workers, generational fairness and the well-being of workers and retirees. The papers focus on different aspects of the retirement and participation decision, but all analyses are based on individual employer or employee data of various European countries. All together, the collection of papers presents a wealth of institutional insights on the nature of pension and labor market reforms in Western Europe, as well as on their intended and unintended effects.

\section{Pension Reforms: Heterogeneity of Effects and Equity Concerns}

Typically, empirical analyses of pension reforms or cross-sectional differences in pension conditions find that workers respond to changes in benefit conditions and changes in statutory pension ages. Three papers in this special issue confirm this stylized fact, offering interesting additional insights on the heterogeneity of effects-both between alternative reform options and between worker group types.

To start with, Andries de Grip, Didier Fouarge and Raymond Montizaan find Dutch public sector employees to increase their expected retirement age as a response to an announced increase in the statutory pension age. In June 2010, the Dutch government signed a new pension agreement with employer and employee organizations to increase the statutory pension age from 65 to 66 years for all inhabitants born after 1954. As the birth date determined the change in eligibility conditions for workers, simply including birth years as controls can be used to obtain causal effects of the reform. For workers that were born between 1954 and 1959, the increase of the average expected retirement age was 3.6 months, whereas workers born after 1959 showed an increase of 10.8 months.

Instead of micro-data on ex ante retirement plans, Alain Jousten and Mathieu Lefebvre use the revealed choices of Belgium workers to analyze the effects of financial incentives. The approach of this study can be characterized as 'semi-structural'. First, based upon information on institutional settings of pension schemes, the authors derive the structural financial option values of retirement, starting from the age of 50. Interestingly, these financial option values also take account the possibility of inflow into the Unemployment Insurance, Disability Insurance, or early retirement packages (if relevant). Second, Jousten et al. include the resulting financial option value functions in Probit models explaining the yearly retirement decision of individual workers. This yields coefficient estimates that can be used to assess the impact of a number of policy measures affecting the option value of retirement. Raising all key eligibility ages for retirement with two years seems most effective in reducing the effective retirement age. It increases the average retirement age with three years. This effect is particularly large for workers who (initially) would have decided to retire relatively early-prior to the age of 60 . In contrast to this, the effects of a benefit cut of $5 \%$ for all pension 
payments are relatively modest. Only very large benefit cuts measure up with changes in eligibility conditions.

The first two studies find a strong heterogeneity in the impact of pension reforms on retirement decisions. According to the analysis of De Grip et al., increases in the expected retirement age are higher for younger workers-suggesting that they are better capable to adapt their retirement plans. The authors also find the response effect to be stronger for women, highly-educated workers and workers with jobs that are not physically demanding. This means that the ex post income consequences for these groups are relatively limited - the decrease in pension rights is offset by a longer working career. Within the context of the policy analysis of Jousten et al., however, impact differences in changes in retirement eligibility originate from differences in (changes of) the financial option value of retirement. These changes are most prominent for workers who-in the absence of reforms - would have retired before they reach the age of 60. The income consequences of not changing their retirement age for this group are substantial.

The analysis of Jousten et al. reveals that the financial consequences of pension reforms vary across worker groups, which in turn will affect the overall income distribution of older workers and retirees. In the paper of Patrick Aubert, Cindy Duc and Bruno Ducoudré, this notion is further explored. Aubert et al. empirically assess the differentiated impact of past French reforms across wage quartiles. For this purpose, they use the meso (or: 'cell-based') simulation model PROMESS, which estimates probability distributions for, amongst others, the age of retirement of workers. In France, age-pension rate profiles vary a lot across pension schemes. Accordingly, there can be large differences in effective retirement ages and pension reforms can have redistributive or counter-redistributive impacts on effective retirement ages. Aubert et al. argue that tightening the work duration criteria for pensions-as was the case in France in 1993 and 2003 - has had a redistributive impact on the income levels of older workers and retirees. In particular, this implied a larger increase in the average retirement age of high-wage workers than for low-wage workers. As to increases of the minimum statutory retirement age, however, the impact is counter-redistributive. This suggests that particularly low-wage workers were hit by this measure.

\section{Generational Fairness and Labor Market Prospects}

Next to the equity effects of pension reforms, another major concern is that of generational fairness. Among most economists, this argument is not very popular-it is often referred to as the well-known 'lump-of-labor-fallacy'. For policymakers, however, pension reforms and labor market reforms targeted at older workers are hard to defend when work opportunities — both for younger and older workers - are limited.

To assess the preferences of early retirement schemes in times of crisis, Harry van Dalen and Kène Henkens use representative surveys among employers in Italy, Germany, Denmark, Poland, The Netherlands and Sweden. Since the 1990s, the common attitude among Western governments was to reverse the early retirement trend. However, now that the recession continues to deepen, the authors find that the old instincts or 'animal spirits' of employers have been reactivated - that is, they consider 
it fair for older workers to step aside to provide younger workers a chance. Next to offering short time work, employers in most countries prefer to offer early retirement packages to older workers. Generational fairness, which is measured in the survey, is most prominent among employers in Italy (50\%), and the lowest in Denmark (13\%). Interestingly, the preference for early retirement packages is not only driven by generational fairness among employers, but also by the strictness of (perceived) employment protection legislation (EPL). The stricter EPL measures are, the more employers will avoid dismissals and opt for early retirement packages and short-time work instead.

Related to the argument of generational fairness, opponents against pension reforms may argue that tightening eligibility criteria-thus prolonging the working life of individuals - will lead to increased dismissals of older workers. Without the option to retire early, employers may opt for the use of other schemes to lay off older workers, with Unemployment Insurance scheme as the most likely candidate. In this respect, Pierre Koning and Max Raterink show in their paper that the job prospects of older workers in this scheme are very limited in the Netherlands. For many workers that were older than 57.5 years of age, the scheme has been a substitute pathway into early retirement for a long time. This raises the question whether the low re-employment rates of older workers is just a fact of life-with older workers that have productivity levels that are too low to find work-or that this is due to the generosity of the Unemployment Insurance scheme, specifically for older workers.

Using registered panel data of Unemployment Insurance spells in the Netherlands from 1998 to 2008, Koning and Raterink estimate linear probability models to unravel the effects of policy changes that aimed at increasing the re-employment rates of older workers. As these policy changes were targeted at older workers, the identification of effects essentially follows from a 'difference-in-difference' design. In doing this, the authors exploit the longitudinal character of their data by specifying age, period and cohort effects. The first policy change entailed the abolishment in 2004 of job search exemptions that were targeted to workers aged 57.5 years and older. The second policy change was a reduction in the potential benefit duration (PBD) in 2006, which particularly affected workers that are older than 55 years of age. Koning and Raterink find that the introduction of search requirements has increased the one-year-re-employment probability of eligible men of 55 years and older with $5 \%$ point, while the reduction in PBD has caused the one-year-re-employment probability to increase with $3 \%$ point. In addition, they show that about $4 \%$ point of the increase in re-employment rate of older workers from 1999 to 2008 is due to birth cohort effects- that is, new cohorts of older workers with higher educational attainment and better health conditions. All in all, both policy measures and birth cohort effects seem to have improved the relative job prospects of older workers, but there still is a long way to go.

\section{Retirement and Well-Being}

The final paper of De Economist of Marzich Abolhassani and Rob Alessie addresses the effect of retirement on the well-being of individuals. Supposing that individuals derive more satisfaction from retirement than from (continued) work, tightening eligibility rules into pension schemes will lower the well-being of individuals. Stated differently, 
these workers would have preferred to retire with less income and more leisure time, but cannot do so. Abolhassani and Alessie use unique micro-data on reported satisfaction in the German Socio-Economic Panel (GSOEP). With these data, they estimate fixed effects panel models that explain the evolution of life satisfaction, changes in life satisfaction, and forecast errors in life satisfaction expectations in the years to come. Most notably, the estimation outcomes do not show evidence for positive or negative effects of retirement on well-being, compared to the option of continued work. Presumably, German individuals who retire seem well prepared, in the sense that the drop in household income they experience is offset by experiencing more leisure. This also suggests that (small) increases in the retirement age will not lead to an increase in the well-being of workers. In contrast - and not surprisingly — there is clear evidence that the transition to unemployment decreases the life satisfaction of workers.

\section{Policy Implications and Research Agenda}

When combining the insights from the different articles, probably the major policy implication is that pension reforms should be well targeted. 'Well-targeted' means that pension reforms should be designed such that behavioral responses are substantial, whereas the ex post financial consequences for workers are limited. Of course, the choice of policy measures will largely be driven by political motives, but one should at least be aware of the heterogeneity of effects - and redistributive consequencesthat come with reforms. At the same time, pension reforms should be accompanied by policies that foster the employment of older workers. Without such complementary policies, there is a high risk that the support for reforms is limited, with both employer and employee organizations demanding for a retraction of policy proposals or even the reintroduction of earlier schemes.

With this in mind, a potentially rewarding research agenda should continue to focus on the interconnectedness between retirement behavior and labor market institutions and outcomes. On the one hand, the evidence on the effects of pension reforms on the use of alternative schemes as substitute pathways, as well as the work opportunities and the types of employment of older workers is limited so far-particularly in countries where the labor participation of older workers has been low for a long time. On the other hand, it is clear that the current economic crisis may affect the use and design of early retirement schemes, and — if retirement age is flexible — the retirement decisions of workers as well. In the years to come, we will witness whether or not this will reverse the reforms that started in the 1990s.

\section{References}

Gruber, J., \& Wise, D. (Eds.). (1999). Social security and retirement around the World. Chicago: University of Chicago Press.

Vandenberghe, V. (2011). Introduction to De ECONOMIST special issue on "Ageing Workforces". De Economist, 159, 89-94. 